\title{
ESPORTE E TV PÚBLICA NO BRASIL: a TV Brasil, a audiência e as transmissões do Campeonato Brasileiro de Futebol da Série C
}

\author{
Priscila Eugênia Trevisan Cestari' \\ Arù José Rocco Júnior²
}

\section{RESUMO}

A TV Brasil é uma emissora pública que pertence à Empresa Brasil de Comunicação (EBC). Foi criada para implantar o Sistema Público de Comunicação no país. Desde 2013 a emissora transmite partidas do Campeonato Brasileiro de Futebol da Série C. O objetivo deste artigo é discutir, à luz de conceitos como audiência, cultura de mídia e valor-notícia, se a emissora cumpre, através do esporte, o papel para o qual foi criada. Para isso, realizamos uma pesquisa qualitativa, exploratória e descritiva, com a análise de documentos internos da emissora e a realização de entrevistas. O estudo pretende contribuir com reflexões a respeito dos processos existentes entre a gestão do esporte e a comunicação pública no Brasil. Assim, procuramos verificar se a emissora cumpre sua missão de formação e fortalecimento da cidadania e da identidade nacional ou se é apenas regida, em seu relacionamento com o esporte, pela ótica comercial da audiência.

Palavras-chave: Esporte. TV Pública. Audiência. TV Brasil. Campeonato Brasileiro Série C.

1 Mestre em Gestão do Esporte. Analista em Comunicação da Empresa Brasil de Comunicação (EBC). São Paulo/ São Paulo, Brasil. E-mail: priscilacestari@yahoo.com.br

2 Pós-doutor em Ciências da Comunicação. Professor da Escola de Educação Física e Esporte da Universidade de São Paulo (EEFE/USP). São Paulo/São Paulo, Brasil. E-mail: aryrocco@usp.br 
SPORT AND PUBLIC TV IN BRAZIL: the TV Brasil, the audience and the broadcasts of Brazilian Série C Championship

\begin{abstract}
TV Brazil is a public broadcaster that belongs to Brazil Communications Company (EBC). It was created to implement the Communication Public System in the country. Since 2013, the station broadcasts Brazilian Série C Championship Football matches. The purpose of this article is to analyze if the issuer meets, through sport, the role for which it was created. For it, we used the concepts of audience, media culture and news value and conducted a qualitative, exploratory and descriptive research with the analysis of internal documents of the issuer and conducting interviews about the theme. The study aims to contribute reflections on the existing processes of management of sport and public communication in Brazil. So we try to verify that the broadcaster fulfills its mission to training and strengthening of citizenship and national identity or whether it is just ruled in their relationship with the sport, from the perspective of commercial audience.
\end{abstract}

Keywords: Sport. Public TV. Audience. TV Brasil Channel. Brazilian Série C Championship.

\title{
DEPORTES Y TV PÚBLICA EN BRASIL: TV Brasil, la audiencia y las transmisiones del Campeonato Brasileño de Fútbol de la Série $C$
}

\section{RESUMEN}

TV Brasil es una cadena pública que pertenece a Empresa Brasil de Comunicacion (EBC). Se creó para poner en práctica el Sistema Público de Comunicación en el país. Desde 2013, la estación transmite partidos del Campeonato Brasileño de Fútbol de la Série C. El propósito de este artículo es analizar, a la luz de conceptos como audiencia, cultura de los médios y valor notícia, si el emisor cumple, a través del deporte, el papel para o cual fue creada. Con este fin, se realizó una investigación cualitativa, exploratoria y descriptiva con el análisis de documentos internos de la entidad emisora y la realización de entrevistas. El estudio pretende aportar reflexiones sobre los procesos existentes de gestión del deporte y la comunicación pública en Brasil. Así que tratamos de verificar que la emisora cumple su misión de formación y fortalecimiento de la ciudadanía y la identidad nacional o de que simplemente se rige en su relación con el deporte, desde la perspectiva de audiencia comercial.

Palabras clave: Deporte. La Televisión Pública. Audiencia. TV Brasil. Campeonato Brasileño de Fútbol de la Série C. 


\section{INTRODUÇÃO}

A TV Brasil é uma emissora pública que pertence à Empresa Brasil de Comunicação (EBC) e foi criada para implantar o Sistema Público de Comunicação no país. A origem da empresa está na fusão da antiga Radiobrás (que contava com duas emissoras de televisão, quatro de rádio e a Agência Brasil) com a TVE do Rio de Janeiro, controlada pela Fundação Roquette Pinto - que, além da TV, gerenciava a Rádio MEC -, e de uma estação de TV educativa no estado do Maranhão, a TVE-Maranhão (BUCCI, 2013). A estreia da TV Brasil aconteceu no dia 2 de dezembro de 2007.

A emissora tem programação de abrangência nacional e está presente em 24 estados mais o Distrito Federal, incluindo emissoras próprias, geradoras e parceiras da Rede Pública de Televisão, com a finalidade de complementar e ampliar a oferta de conteúdo audiovisual, além de oferecer uma programação com abordagem informativa, cultural, artística, científica e cidadã. A programação é estruturada a partir de cinco eixos principais: arte, conhecimento, esportes, infantil e informação (EBC, 2015).

Desde 2013, a TV Brasil transmite as temporadas do Campeonato Brasileiro de Futebol da Série C em televisão aberta, enquanto a transmissão esportiva das séries A e B (primeira e segunda divisão), neste mesmo sistema, está sob a responsabilidade das emissoras privadas. As emissoras compram os direitos de transmissão de um campeonato em troca de audiência e retorno financeiro, por meio da negociação de cotas de publicidade (SAVENHAGO, 2011).

Na terceira divisão nacional e no Campeonato Brasileiro Feminino de Futebol, produtos da TV Brasil, os clubes participantes não recebem remuneração de TV para ter os jogos transmitidos. Por essa razão, aproveitam a oportunidade da exposição em canal aberto para melhorar a relação entre o time, patrocinadores e torcedores.

Considerando este contexto, este artigo pretende analisar a relação entre o Esporte e a TV Pública, tendo como objeto de estudo o Campeonato Brasileiro de Futebol da Terceira Divisão (Série C), transmitido pela TV Brasil. Por esta razão, questiona-se: ao contar com transmissões de futebol na programação, como a TV Brasil cumpre sua missão enquanto TV pública e de que forma isso contribui para a visibilidade e audiência da emissora?

O objetivo é verificar se a missão da EBC, que é a de criar e difundir conteúdos que contribuam para a formação crítica das pessoas (EBC, 2015), a visão da empresa (ser referência em comunicação pública) e seus valores (entre eles, o compromisso com a comunicação pública, independência nos conteúdos, valorização das pessoas e da diversidade cultural brasileira) são coerentes com a proposta da produção no esporte em uma emissora pública, que tem por objetivo contribuir com a formação da cidadania.

A proposição é a de que os eventos esportivos transmitidos ao vivo atraem telespectadores interessados nos jogos que também não costumam estar na mídia comercial. E que, por ser uma emissora de canal aberto, a TV Brasil segue esse caminho para se tornar conhecida em todo o país. Mas, nesse sentido, o futebol pode ser considerado um produto comercial, que visa a audiência, ou um produto social e de divulgação dos valores do esporte das mais diversas regiões do país? 
O assunto é relevante por se tratar de uma pesquisa inédita no contexto de uma TV pública nacional e que pode ser uma alternativa às emissoras comerciais que tem sua produção voltada às necessidades do mercado e não do cidadão. Ao pensarmos na relação existente entre a televisão e o esporte, busca-se identificar se o investimento em transmissões relacionadas ao futebol é uma maneira de atrair telespectadores, por ser a modalidade a prática esportiva mais acompanhada pelos brasileiros e um dos aspectos da cultura que mais interfere na vida social das pessoas, assim como na formação da própria cultura de um país (ROCCO JÚNIOR, 2014). Desde o seu início no Brasil, o futebol representava valores, sejam sociais ou raciais, políticos ou de lazer, dentro ou fora do campo de jogo presentes na sociedade, transformando-se em esporte de massa.

Para entender a relação entre o esporte e a TV Pública, contextualizou-se o surgimento deste veículo no país e em alguns outros países. Os conceitos de audiência, cultura de mídia e valor-notícia serão as referências para a base desta que é uma pesquisa qualitativa, exploratória e descritiva, realizada a partir de levantamento bibliográfico e análise de documentos como relatórios internos da EBC. Como fonte de dados primários, foram realizadas entrevistas com três profissionais: 1) gerente-executivo da EBC; 2) especialista na área de Comunicação; e 3) professor e profissional com experiência na área de Gestão do Esporte, para avaliar a adequação, ou não, das estratégias relacionadas à transmissão de eventos esportivos e visibilidade por parte da TV Brasil. As conclusões deste estudo estão baseadas na combinação de todos os elementos já mencionados, em especial às entrevistas e sua relação com o referencial teórico pesquisado.

O estudo pretende contribuir com reflexões a respeito dos processos existentes entre a gestão do esporte e a comunicação pública. Ao buscar maior atenção e alinhamento entre a missão da TV Brasil e as transmissões esportivas que realiza, com enfoque na formação da cidadania, espera-se compreender com mais clareza o posicionamento do esporte na TV pública. Com isso, é possível verificar se a emissora cumpre sua missão de formação e fortalecimento da cidadania e da identidade nacional ou se é apenas regida, em seu relacionamento com o esporte, pela ótica comercial da audiência.

\section{O PAPEL DA TV PÚBLICA, A EBC E A TV BRASIL}

No mundo, as televisões púbicas surgiram antes mesmo das emissoras comerciais. A BBC na Inglaterra, a TVE espanhola, a France Televison, a RTP de Portugal, a ARD e a ZDF, alemãs, por exemplo, nasceram como televisões estatais, controladas pelos governos nacionais (VERÁS; JUNIOR, 2011). Na América do Norte, outras experiências da radiodifusão pública também se destacam: a Public Broadcasting Service (PBS), nos Estados Unidos, e a Canadian Broadcasting Corporation (CBC), no Canadá.

A mais conhecida é a BBC (British Broadcasting Corporation), criada em 1922, dirigida até hoje por um conselho diretor formado por representantes da sociedade inglesa e que é nomeado pela "ordem real" (LEAL FILHO, 1997). A emissora é financiada por uma 
taxa anual de contribuição para o sistema público e a cada dez anos, há a renovação da carta de concessão (NAZARENO, 2007; ORTIZ, 2010).

Em Portugal, o serviço público de radiodifusão é responsabilidade da RTP (Rádio e Televisão de Portugal) desde 1935. Diferentemente do modelo inglês, a gestão da empresa é feita por uma assembleia geral de acionistas e um conselho administrativo com funções executivas (ORTIZ, 2010; MOYSÉS et al., 2009). Enquanto na Espanha, a corporação de Rádio y Televisión Española (RTVE) atua em âmbito nacional no sistema público de comunicação, mas também existem empresas de radiodifusão regionais, ligadas às comunidades autônomas do país (ORTIZ, 2010). O sistema de financiamento da RTVE é baseado em ingressos comerciais e verbas orçamentárias aprovadas pelo Congresso (MOYSÉS et al., 2009). Ao contrário do que ocorreu na Europa, as iniciativas para implantar serviços públicos de radiodifusão no Brasil estavam subordinadas ao modelo comercial, atuando de forma complementar (LEAL FILHO, 2007). Pela legislação brasileira, o controle da radiodifusão é público e cabe ao Poder Executivo conceder e renovar concessões de acordo com o artigo 223 da Constituição Federal de 1988. Ao Executivo compete "outorgar e renovar concessão, permissão e autorização para os serviços de radiodifusão sonora e de sons e imagens, bem como aprovar as transferências diretas e indiretas das outorgas, observado o princípio da complementaridade dos sistemas privado, público e estatal" (SENADO FEDERAL, 1988).

Apesar de o artigo 223 estabelecer esses sistemas, principalmente o público e o estatal, precisam ser distinguidos por algum critério e atuar de forma complementar. O sistema estatal tem características não-comerciais, pelo atendimento das finalidades educativas, informativas e culturais previstas no artigo 221 da Constituição Federal (idem, 1988) com programação voltada à divulgação e transparência dos atos institucionais e à prestação de contas da administração pública em suas três esferas de poder: o Executivo, o Legislativo e o Judiciário (CARTA DE BRASÍLIA, 2007).

O sistema público, não-estatal, seria aquele que opera também sem intenção de lucro, mas as diretrizes de gestão da programação e a fiscalização devem ser atribuição de órgão colegiado deliberativo, representativo da sociedade, no qual o Estado ou o governo não devem ter maioria (CARTA DE BRASíLIA, 2007). Da Silva Lopes (2015) ressalta que não se deveria ocultar do estatal a dimensão pública, pois se "a televisão pública é uma instituição do Estado ou do poder executivo federal, por conseguinte será uma instituição financiada e/ou mantida com o dinheiro público, ou do público, logo é pública" (LOPES, 2015 , p.24). Otondo (2012) complementa ao propor que uma televisão de serviço público deveria ter independência editorial e de gestão, universalidade, pluralismo, continuidade, igualdade e transparência.

Com a edição da Medida Provisória 398, em 25 de outubro de 2007, posteriormente convertida pelo Congresso na Lei 11.652/2008, foi autorizada a criação da Empresa Brasil de Comunicação (EBC). Ao herdar os canais de rádio e TV da estatal Radiobrás e da TVE do Rio de Janeiro, a EBC ficou encarregada de unificar e gerir as emissoras federais já existentes, instituindo o Sistema Público de Comunicação (MOYSES et al., 2009).

Em relação ao financiamento, de acordo com a Lei 11.652/2008, as fontes de recursos para a EBC são: orçamento federal (dotação orçamentárias da União), além de receitas 
próprias com publicidade institucional, patrocínios culturais, prestação de serviços para a administração federal, como clipping diário de notícias, e recursos de acordos e convênios realizados com entidades nacionais, internacionais, públicas e privadas. A estrutura gestora da EBC é formada por: Assembleia Geral; Órgãos da Administração (Conselho de Administração e Diretoria Executiva) e Órgãos de Fiscalização (Conselho Curador, Conselho Fiscal e Auditoria Interna). Além disso, adquiriu como missão articular e implantar a Rede Nacional de Comunicação Pública. O surgimento da TV Brasil e o lançamento da TV Digital em São Paulo aconteceram simultaneamente, no dia 2 de dezembro de 2007.

As emissoras públicas foram criadas para proteger a vitalidade dos debates e das manifestações culturais que a sociedade deve pautar, produzir e preparar em seu domínio civil próprio, independentemente do Estado e também do mercado (BUCCl, 2010). O jornalista e ex-presidente da Radiobrás defende que "uma emissora pública existe porque as pessoas têm direito (como autoras, agentes ou espectadoras) à informação jornalística, ao conhecimento e às manifestações culturais" (p. 05). A relação com o governo que delega o serviço e ao mesmo tempo deve dar os recursos e a liberdade necessária para cumprir a missão e funções "é um ponto nevrálgico do cotidiano da TV Pública" (OTONDO, 2012, p.50).

Bucci (2010) aponta que o caráter verdadeiramente público de uma emissora de radiodifusão é a gestão independente. Para ele, "o negócio da televisão pública não é entretenimento e, indo mais longe, não é sequer televisão: é cultura, é informação, é liberdade" (idem, 2010, p. 17). Portanto, uma TV Pública poderia ser uma opção ao modelo de televisão comercial ao oferecer uma programação de qualidade sem se preocupar com a audiência que geralmente é estabelecida - e cobrada - pelo mercado.

\section{Esporte na TV: Audiência, Valor-Notícia e Cultura de Mídia}

Com o surgimento da comunicação de massa, o esporte se tornou um espetáculo para ser assistido. A Copa do Mundo de Futebol, por exemplo, é o evento esportivo de maior audiência do planeta. A final do Mundial de 2014 entre Alemanha e Argentina, no Estádio do Maracanã (RJ) foi vista por mais de um bilhão de pessoas em todo o mundo. Na Alemanha, a partida foi o evento mais visto da história da televisão local, com 34,7 milhões de telespectadores (CHADE, 2014).

Pesquisa anual realizada pela Secretaria de Comunicação da Presidência da República, que fez um levantamento dos hábitos de consumo de mídia pela população brasileira, identificou que os brasileiros assistem à televisão, em média, $4 \mathrm{~h} 31$ por dia, de $2^{\mathrm{a}}$ a $6^{\mathrm{a}}$-feira. Nos finais de semana, são $4 \mathrm{~h} 14$, sendo que a maior parte desses indivíduos faz isso todos os dias da semana (73\%) (BRASIL, 2014). As pessoas assistem à televisão, principalmente, "para se informar (79\%), como diversão e entretenimento $(67 \%)$, para passar o tempo livre (32\%) e por causa de um programa específico (19\%)". (idem, 2014, p.15).

O conceito de audiência se tornou o principal parâmetro para a medição do grau de sucesso de determinado programa televisivo (DE AGUIAR; PROCHNIK, 2010). Dentro de questão da audiência, é importante destacarmos o valor-notícia, que faz parte da cultura jornalística, está presente em todo o processo de produção editorial e se refere aos critérios 
que os jornalistas utilizam na seleção dos acontecimentos que devem ir ao ar nos programas jornalísticos da televisão (TRAQUINA, 2005). É dessa forma que um acontecimento se torna candidato a se tornar notícia em detrimento de outro. A relevância do fato (ou do assunto a ser discutido) determina que a noticiabilidade tem a ver com a capacidade de o acontecimento incidir, ou ter impacto, sobre as pessoas, sobre o país, sobre a nação.

Por isso, compreender qual é o público que será atingido pela audiência não é a mesma coisa que estudar esse público, apesar de que as audiências e públicos, muitas vezes, são compostos dos mesmos espectadores (DAYAN, 2001). No artigo The peculiar public of television, o cientista social questiona se as audiências da TV são capazes de se transformarem em público e vai um pouco mais além quando pergunta "se o fato de os telespectadores formarem um público pode interessar a emissora a elaborar produtos respeitando suas preferências" (p. 5).

Uma emissora que se pauta pela audiência contribui para exercer sobre o consumidor as pressões do mercado. Por outro lado, é importante que haja o retorno do que é produzido e exibido ao telespectador. O que acontece, muitas vezes, é que o canal público acaba sendo um veículo para programas que não são passíveis de existir nas emissoras comerciais. A busca e a otimização desses recursos específicos podem ser norteadores para uma TV pública, aproveitando-se do futebol para que a emissora possa ser conhecida e, quem sabe, registrar índices de audiência significativos.

Denis de Moraes, relaciona diretamente o poder da mídia e sua influência no crescimento do esporte (BRITTOS; CABRAL, 2008). Para o pesquisador em comunicação, a associação entre esses setores gera aumento de pessoas interessadas nos eventos que são transmitidos. Para reforçar essa ideia, Moraes cita, ainda, uma declaração de Rupert Murdoch, proprietário da News Corportation - conglomerado de mídia presente em vários países - sobre o porquê a indústria do esporte segue cada vez mais atrelada ao poder da comunicação televisiva: "O esporte é o melhor chamariz para a televisão. Dá sobrecarga ao restante da programação, pois incentiva os telespectadores a assinarem TV a cabo ou por satélite" (BRITTOS; CABRAL, 2008, p.118).

Rein, Kotler e Shields (2008) reconhecem que a mídia se transformou no canal mais acessível aos fãs no mundo dos esportes e por essa razão é um canal dominante para os torcedores. O apelo universal que o esporte exerce sobre as pessoas despertou um interesse crescente na mídia e por isso "a programação esportiva na televisão ocupa uma proporção significativa em sua grade" (REIN et al, 2008, p. 188). Por essa razão, a televisão continua tendo papel central na indústria esportiva, pois é encarada pelas empresas como um meio de conseguir maior exposição e de avaliar o retomo do investimento realizado no esporte (POZZI, 1996).

O futebol pode ser visto como integrante da cultura e da sociedade brasileira. Da Matta destaca que "não foi por mero acaso que o esporte como um domínio social (e como uma indústria cultural) tenha surgido acasalado com o advento da sociedade industrial de mídia e de massa" (DA MATTA, 1994; p.14). Na sociedade pós-moderna, o discurso dos meios de comunicação de massa está cada vez mais relacionado com o produto esportivo (ROCCO JÚNIOR, 2013). E parte da modernidade e a época atual são a sociedade do espetáculo, do consumo e da fragmentação (BAHIA, 2005). 
O esporte profissional é um dos maiores espetáculos da cultura de mídia (KELLNER, 2007). Para o filósofo norte-americano, especialista em história e fenômenos culturais, o esporte é uma das áreas que fazem parte do espetáculo com eventos como os Jogos Olímpicos, o Super Bowl (final do Futebol Americano), a Copa do Mundo e a NBA, atraindo grande público e, ao mesmo tempo, gerando altas verbas publicitárias. Para o autor, novos modelos de experiência, inclusive no esporte global, produzem a chamada "nova cultura do espetáculo com o surgimento de diversos espetáculos, de megaespetáculos e de espetáculos interativos" (p.11).

Para Kellner (2011), foi a partir do surgimento da televisão que a mídia se transformou em força dominante na cultura, na socialização, na política e na vida social. Segundo o pesquisador, na sociedade norte americana, a mídia veicula uma forma comercial de cultura, "produzida por lucro e divulgada à maneira de mercadoria" (idem, 2011, p. 27).

A partir do momento em que o esporte é comercializado, os espectadores passam a ser em maior número do que os participantes e, de certa forma, são o público-alvo da mídia televisiva. Para Pierre Bourdieu (1997), o espetáculo é produzido duas vezes: primeiro, no local e no instante do fato, por todo conjunto envolvido (atletas, comissão técnica, juízes, organizadores) na competição; segundo, por aqueles que transformam as imagens em discursos desse espetáculo.

O autor reforça ainda que, quando o esporte é aplicado aos produtos de massa, ele retorna ao espectador sob forma de espetáculo, se o valor coletivamente reconhecido à prática de esportes (principalmente depois que as competições esportivas se tornaram uma das medidas da força relativa das nações, ou seja, uma disputa política) não contribuísse para mascarar o divórcio entre a prática e o consumo e, ao mesmo tempo, as funções do simples consumo passivo (BOURDIEU, 1997, p. 09).

Enquanto as emissoras privadas compram os direitos de transmissão de campeonatos de futebol em troca de retorno financeiro e de audiência, emissoras públicas poderiam transmitir eventos esportivos para divulgar sua proposta e programação. Apesar de se utilizar da linguagem do espetáculo (idem, 1997), uma TV Pública pode ser uma possibilidade para gerar identificação com o que é transmitido, mas pela proposta de construir uma comunicação pública com referência aos conceitos de missão, visão e valores.

\section{MATERIAL E MÉTODOS}

Para responder qual a relação entre o esporte e a TV Pública e atingir o objetivo desse artigo, que é identificar se por meio das transmissões esportivas a TV Brasil cumpre sua missão enquanto emissora de caráter público, a abordagem utilizada para esta pesquisa foi qualitativa, de caráter exploratório e descritiva.

A pesquisa qualitativa não se preocupa com representatividade numérica, mas, sim, com o aprofundamento da compreensão de um grupo social ou de uma organização e com aspectos da realidade que não podem ser quantificados, centrando-se na compreensão e explicação da dinâmica das relações sociais (GERHARD; SILVEIRA, 2009). 
Creswell (2010) descreve quatro tipos básicos de dados a serem coletados em uma pesquisa qualitativa: observação, entrevistas, documentos e materiais audiovisuais. As observações qualitativas são aquelas em que o pesquisador faz anotações de campo sobre o comportamento e as atividades dos indivíduos no local da pesquisa. Nas entrevistas qualitativas, o pesquisador conduz entrevistas pessoalmente, por telefone ou por meio de grupo focal, que envolvem questões não estruturadas e em geral, abertas. Além disso, o pesquisador pode coletar documentos qualitativos (jornais, relatórios oficiais) ou documentos privados (correspondências, e-mails). Materiais audiovisuais (fotos, áudio, vídeo) podem ser outra categoria de dados a serem coletados em uma pesquisa qualitativa.

Para este estudo, foram realizadas coleta de documentos internos da EBC e entrevistas. Em um primeiro momento, foram coletados dados primários a partir de relatórios da $E B C$ relacionados às atividades da empresa relacionadas à transmissão esportiva, além de relatórios da Ouvidoria da EBC produzidos nos períodos entre 2014 e 2015, em que há relatos e contribuições de cidadãos que acompanham a programação da TV Brasil. A Ouvidoria é responsável por receber, examinar e encaminhar reclamações, elogios, sugestões, comentários e pedidos de informação referentes aos conteúdos de todos os veículos geridos pela $\mathrm{EBC}$, seja televisão, rádio ou agência de notícias.

As entrevistas aconteceram no mês de novembro de 2015, sendo que duas delas foram realizadas de forma presencial e uma por meio eletrônico, todas com as devidas autorizações para publicação. A opção pela alteração ao método de entrevista deveu-se à agenda de compromissos do profissional e que não possibilitaram o encontro presencial. Foram realizadas com três profissionais: 1) gerente executivo da $\mathrm{EBC}$; 2) profissional de comunicação e funcionário da EBC; e 3) professor e ex-gestor esportivo, com o objetivo de identificar quais as visões destes profissionais quanto ao papel e as transmissões esportivas de uma TV Pública. O roteiro das entrevistas foi semiestruturado e desenvolvido pelos pesquisadores, a partir dos conceitos teóricos e referências sobre TV Pública, audiência, valor-notícia e cultura de mídia. Por meio das entrevistas individuais, foi possível alcançar uma variedade de impressões e percepções em relação aos conceitos levantados.

Como estratégia de interpretação, utilizou-se o método de análise de conteúdo que, segundo Bardin (2007) consiste em um conjunto de técnicas de análise das comunicações que utiliza procedimentos sistemáticos e objetivos de descrição do conteúdo das mensagens. A análise de conteúdo, além de realizar a interpretação após a coleta dos dados, desenvolve-se por meio de técnicas mais ou menos refinadas (FLICK, 2009). E para isso, há a necessidade de categorizar os elementos, para em seguida agrupá-los como definido por Vergara (2012).

A partir do levantamento bibliográfico, foram elaboradas questões voltadas aos especialistas da área de gestão, do esporte e da comunicação, assim como questões voltadas para o gestor da EBC. Após a realização das entrevistas, o material foi transcrito e para a análise deste conteúdo, foram feitas a categorização dos seguintes termos: TV Pública, audiência, TV Brasil (aspectos positivos e negativos), esporte e futebol. 


\title{
RESULTADOS E DISCUSSÕES
}

A abordagem do esporte na EBC considera "as variadas modalidades praticadas em todo o país e deve manter sintonia com as recomendações da Política de Esportes da EBC, estabelecida pela resolução 03/10, do Conselho Curador" (EBC-MANUAL DE JORNALISMO, 2013, p.59). Os fatos do universo esportivo que devem ser pautados pelo jornalismo estão distribuídos em duas vertentes: conteúdo esportivo que integra o contexto do esporte (temas ligados às competições, comportamento, economia, entre outros) e o esporte que as pessoas praticam (que os veículos da EBC devem reportar, analisar e, oportunamente, transmitir, considerando-os como fatores de promoção da saúde, mobilização, integração e inclusão social, educação, desenvolvimento humano e lazer.) (p. 60).

As premissas da EBC para a cobertura esportiva são:

\begin{abstract}
O esporte não se resume ao futebol profissional, mesmo sendo a o esporte que mais envolve e mobiliza a população. A EBC deve dirigir sua atenção para os mais variados esportes e suas modalidades; 2 ) O esporte não se limita às práticas de alto rendimento; 3) $\mathrm{O}$ jornalismo da $\mathrm{EBC}$ deve reportar as iniciativas públicas ou privadas que levem à prática do esporte pelo cidadão; 4) A cobertura dos eventos deve propiciar ao jornalismo da EBC incluir informações que possam despertar o interesse do torcedor por ações de cidadania; 5) Na vida moderna, que tende a reduzir atividades físicas, é importantíssima a promoção do esporte como contribuição no combate à vida sedentária e no incentivo à convivência entre pessoas, cada vez mais isoladas pelo uso individual de computadores e outras tecnologias; 6) O jornalismo da EBC deve incluir pautas sobre a formação de atletas para as seleções olímpicas e esportes profissionais mostrando os caminhos disponíveis para acesso e suas dificuldades; 7) Dedica atenção às questões relativas à violência nos estádios e quadras esportivas, condições de conforto e segurança dos locais dos eventos esportivos; 8) Oferece ao público análises independentes, sem o elogio ou crítica fáceis e sem atender a objetivos de marketing; 9) As práticas esportivas das pessoas com deficiência devem ser cobertas pelo jornalismo da EBC em igualdade de oportunidades com as que são praticadas pelas demais pessoas (EBC-MANUAL DE JORNALISMO, 2013, p.24).
\end{abstract}

Apesar da existência destas nove premissas para a cobertura esportiva pelo jornalismo da TV Brasil, não há nenhuma exclusiva para as transmissões de eventos esportivos, que estão ligados diretamente à Gerência Executiva de Esporte. Na EBC, três plataformas cobrem sistematicamente o universo esportivo: o Portal EBC, as rádios e a TV Brasil, sendo que as Rádios e TV contam com um Núcleo integrado, pertencente à Diretoria de Jornalismo e responsável pela transmissão dos eventos esportivos (CRISPI, 2014). Subordinada à Diretoria de Jornalismo (DIJOR) da EBC, compete à Gerência Executiva de Esporte "planejar, supervisionar e controlar as atividades de captação, produção e cobertura de conteúdo de eventos esportivos e negociar os direitos de transmissão (EBC, 2015, p. 27).

No Plano Estratégico 2012-2020 foram definidas a missão, os valores e visão da EBC, conforme apresentado na Tabela 1, sustentados pelos princípios determinados na Lei $n^{\circ} 11.652 / 2008$, que criou a empresa e que definem os propósitos como "agente produtor e promotor de Comunicação Pública (EBC, 2012). 
Tabela 1 - Missão, Visão e Valores da EBC

\begin{tabular}{l|c}
\hline Missão & Criar e difundir conteúdos que contribuam para a formação crítica das pessoas. \\
\hline Visão & Ser referência em Comunicação Pública \\
\hline Valores & Temos compromisso com a comunicação pública. \\
& $\begin{array}{c}\text { Praticamos a independência nos conteúdos, a ética, a } \\
\text { transparência e a gestão participativa. } \\
\text { Defendemos os direitos humanos, a liberdade de } \\
\text { expressão e o exercício da cidadania. }\end{array}$ \\
& $\begin{array}{r}\text { Valorizamos as pessoas e a diversidade cultural e regional brasileira. } \\
\text { Cultivamos a criatividade, a inovação e a sustentabilidade. }\end{array}$ \\
\hline
\end{tabular}

Fonte: os autores, com base no Plano Estratégico 2012-2020 (EBC, 2012)

Mas de que forma um agente produtor e promotor da Comunicação Pública pode vir a ser conhecido da população? Pesquisa realizada pelo Instituto Análise, a pedido da Secretaria de Comunicação da Presidência da República, a qual a EBC é subordinada, fez um diagnóstico de como a imagem da $\mathrm{EBC}$, seus produtos e veículos são percebidos pela população. E se os valores da EBC, descritos no Planejamento Estratégico, são identificados na programação da TV (EBC, 2015).

Desde 2010, quando a emissora transmitiu os primeiros jogos da Série C até o último campeonato, disputado em 2015, buscou-se compreender os motivos que levaram uma TV Pública a investir nesse tipo de evento e de que forma sua missão está ou não presente nas transmissões esportivas.

As primeiras transmissões do Campeonato Brasileiro da Série C na TV Brasil ocorreram no ano de 2010. De acordo com o gerente-executivo entrevistado para essa pesquisa, e que acompanhou a implantação do projeto, o entendimento de se colocar futebol na grade de programação era o de oferecer um produto que ninguém, ou pouca gente, nas emissoras comerciais, tinha interesse em veicular.

O elemento principal estava ligado ao mandato da EBC, que é a regionalização. $\mathrm{Na}$ Lei que criou a empresa, o artigo $3^{\circ}$ reforça essa proposta: a de promover a cultura nacional, já que muitos times eram do Norte e Nordeste na Série C. Segundo o gerente-executivo entrevistado para esta pesquisa, esta foi uma maneira de ampliar o horizonte de interesse da empresa. Originalmente essas transmissões abriram uma pista para cobertura de outra natureza, "que não exclusivamente esportiva, na área jornalística, de variedades, em um esforço de promover a integração da produção cultural do esporte, dentro dessa produção cultural desses estados que se integravam à Rede Pública".

No relatório da Ouvidoria, de abril de 2014, o então ouvidor-adjunto Márcio Godinho destaca a aquisição dos direitos de transmissão dos jogos da Série $C$ do Campeonato Brasileiro. Para ele "a iniciativa da TV Brasil tem a finalidade de contemplar essa parcela importante da população [a de telespectadores que torcem para times da Série C], de valorizar os clubes e suas torcidas, de contribuir para a elevação de sua autoestima, além, evidentemente de tornar mais conhecida a nossa emissora pública, o que pode resultar no aumento dos índices de audiência de outros programas da grade" (EBC, 2014a, p. 8). 
No mesmo documento destaca-se uma série de problemas identificados durante a primeira transmissão de uma partida da Série C, em 2013, entre duas equipes da Paraíba: Treze, de Campina Grande e Botafogo de João Pessoa. Os comentários foram enviados por telespectadores para a Ouvidoria da EBC, relatando vários episódios - desde problemas técnicos até a imparcialidade da equipe de transmissão. Apesar do investimento nas transmissões dos jogos, o ouvidor-adjunto ressalta que é necessária a capacitação da equipe, mas que "antes de mais nada, é preciso encontrar os meios - oficinas, seminários, encontros - para que toda a equipe absorva o que prevê a Lei 11.652, que institui os princípios e objetivos dos serviços de radiodifusão pública, a Norma da Rede Nacional de Comunicação Pública/Televisão e as diretrizes consolidadas no Manual de Jornalismo da EBC" (EBC, 2015, p.11).

Segundo análise de documentos internos, no ano de 2013, a Ouvidoria recebeu um total de 7017 mensagens e, destas, 199 referiam-se a esportes e campeonatos. No primeiro trimestre de 2014, foram 1585 contatos, sendo 24 deles sobre a cobertura esportiva da EBC (CRISPI, 2014). A manifestação dos telespectadores dá-nos uma dimensão de que há público interessado nas transmissões do futebol da TV Brasil, mas nota-se que a emissora ainda está distante de satisfazer a população que, por meio das transmissões da Série C, tem a oportunidade de ver seus os times na televisão.

Mas, ao mesmo tempo que as partidas atraem os torcedores para as transmissões, os torcedores se transformam em telespectadores que se manifestam por meio da Ouvidoria. No relatório do mês de outubro/2015, foram citadas críticas de nove telespectadores ao narrador e comentaristas da TV Brasil. Eles alegavam que "ambos tinham postura de torcida explícita pelo Fortaleza, na partida contra o Brasil de Pelotas, pela Série C" (EBC, 2015, p.23).

Apesar de a Ouvidoria ter feito a análise e concluído que de fato houve um posicionamento explícito da equipe de transmissão e de servir como exemplo de como os jogos não devem ser narrados nem comentados, no mês seguinte, 11 telespectadores enviaram mensagens criticando, mais uma vez, a parcialidade da transmissão. (idem, 2015).

Ao rever a transmissão da decisão do Campeonato Brasileiro da Série $C$, entre Vila Nova (GO) e Londrina (PR), a Ouvidoria identificou que "tanto o narrador quanto os comentaristas fizeram um primeiro tempo absolutamente equilibrado. Não privilegiaram nenhuma das equipes. Um dos comentaristas, sim, deu a entender que torcia para o Vila Nova e divulgava apenas números do campeonato favoráveis ao clube" (EBC, 2015, p.24).

A partir dessa manifestação, o segundo comentarista reagiu falando sobre o Londrina, buscando um equilíbrio nas informações. Após o Vila Nova marcar mais dois gols (o placar final foi de $4 \times 1$ para a equipe goiana) e o narrador, além de parecer vibrar em excesso com o resultado, ainda concluiu: "O Vila bota o Londrina de quatro no Serra Dourada". Apear do equilíbrio identificado durante a maior parte da transmissão, foi "jogado fora no finalzinho do jogo com apenas uma frase" (idem, 2015, p.24-25).

Ao analisar o relatório da Ouvidoria, com base na análise de monitoramento e análise de conteúdo, de Novembro/2015, das 95 demandas destinadas à TV Brasil, 27 foram sobre a transmissão do futebol (séries B, C, D e futebol feminino). Destas, 11 
foram reclamações de narração tendenciosa, três reclamações sobre divulgação errada do horário; duas reclamações sobre a não transmissão via TV Web; uma reclamação sobre o sinal durante a transmissão; três pedidos de informação; dois comentários; quatro elogios, sendo três ao Futebol Feminino; e uma sugestão (EBC, 2015, p.48).

Contar com partidas de futebol na grade de programação também dá oportunidade de divulgação à TV Brasil, atraindo público para a emissora. Em entrevista à Revista do Conselho Curador - instrumento de participação da sociedade na gestão de empresas públicas de comunicação - o então Gerente Executivo de Esportes da EBC, Carlos Alberto Gomes, pontuou que "o caminho para o esporte na TV pública é ter eventos esportivos, mas investindo mais em esportes amadores. Temos que ter uma TV que é vista e o esporte pode trazer isso" (CRISPI, 2014). Para o gestor, o "público que é conquistado pelo espetáculo, acaba ficando para ver outras programações da emissora" (p.13).

$\mathrm{Na}$ pesquisa realizada pelo Instituto Análise, existem alguns vieses na imagem da emissora que funcionam como barreiras para um maior interesse ou motivação em conhecê-la mais a fundo (BRASIL, 2015, p.38), tais como:

Ser uma TV do Governo Federal que, supostamente, não teria autonomia editorial ou programática e sim um viés político e ideológico; 2) Imagem de uma emissora ultrapassada, "antiquada", desatualizada. Essa percepção se dá, exclusivamente, em virtude da qualidade da imagem e do áudio e provoca uma desmotivação para continuar assistindo; 3) Imagem de que seria uma emissora similar às TVs Câmara e TV Senado, por estarem todas sequenciadas na numeração de canais. E nessa perspectiva, todas teriam uma programação exclusivamente focada em política e não atrativa.

Esses pontos apontados pela pesquisa contam com similaridades apontadas pelos especialistas entrevistados para este estudo. Em relação ao conceito de TV Pública, o profissional de Comunicação entrevistado destaca que "a TV Pública tem também o papel pedagógico de formar um telespectador mais crítico". Dessa forma, há uma atenção a necessidade de uma narrativa diferenciada em relação à apresentada pela mídia comercia.

O gerente-executivo considera "que as pessoas desconhecem o que é TV Pública, por isso é necessária uma comunicação dirigida para que esse conceito seja entendido por meio de informação qualificada e produtos que mostrem que a emissora não é "chata" ou 'cabeça'". E, além disso, a TV Pública deveria atender os interesses do povo brasileiro, em todas as regiões e estados do país, para serviço público.

Mazzioti (2002) defende que há pelo menos três princípios que se inter-relacionam em uma televisão pública dirigida à construção da cidadania: estabelecer uma programação de qualidade; ocupar os espaços vagos deixados pela televisão comercial, refletindo na questão de gênero com intenção de educar ou conscientizar; e, considerar a diversidade cultural, tolerância e abertura a outros assuntos culturais, respeitando e abordando diferenças étnicas, de classes sociais, gênero, idade, de maneira plural.

Os conteúdos que não caberiam na TV comercial não são necessariamente os conteúdos chatos, segundo Bucci (2010). Para o jornalista, “a televisão pública não 
deveria temer a chatice como um abismo. A chatice é um tabu do entretenimento, mas não é exatamente uma barreira do pensamento. [...] A chatice é o vício da televisão comercial, a peste de que ela foge obstinadamente, de tal modo que todos os canais parecem iguais. O primeiro dever da televisão pública é ser diferente disso. A experimentação estética, um dever que ela tem, não pode conviver com o medo da chatice ou com o imperativo de agradar às maiorias médias o tempo todo" (BUCCl, 2010, p.18).

Martín-Barbero (2001) reforça a ideia de que uma televisão pública precisa alcançar todo o país, apoiada nas possibilidades que a tecnologia oferece, de forma que a televisão seja uma "rede que circule e que ocorra tanto na periferia, e das periferias em direção ao centro" (p. 17). E se não há possibilidade de melhorias em locais remotos, que as emissoras públicas cheguem por meio de parcerias.

No caso da EBC, a cobertura no sistema em transmissão aberta chega a 125 milhões de pessoas, o que é fruto da associação da empresa com emissoras que estão ligadas aos governos estaduais, além de emissoras educativas privadas. A TV Brasil encabeça a Rede Pública de Televisão (RPTV), que conta com emissoras geradoras e retransmissoras parceiras de 24 estados, mais o Distrito Federal. Amapá e Rondônia ainda não contam com o sinal da TV Brasil, segundo o gerente-executivo porque o "sistema público inexiste nestes lugares, mas já existe o esforço da associação da EBC com universidades locais para que esta lacuna seja preenchida".

Sobre a audiência, os especialistas concordam que ela é baixa. Chegar a todos os domicílios brasileiros e se tornar conhecida da população são desafios a serem enfrentados pela TV Pública. O gerente-executivo reconheceu que "quando você trabalha com audiências residuais é difícil de a gente precisar se o fator contingente aleatório interferiu no melhor desempenho ou não ou se aquilo tem a ver, se esse aumento tem a ver com o interesse específico daquele programa, daquele produto".

Não há conhecimento de levantamento que mensure se a audiência de determinado programa influencia em outro. De maneira geral, a transmissão esportiva atrai a atenção, já que o telespectador costuma se interessar pelo produto de forma específica. Como destaca Da Matta (1994), é através do "jogo de futebol" que as massas brasileiras podem experimentar vencer com seus times favoritos" (p.17).

De acordo com a Resolução nº 02/2015, do Conselho Curador da EBC, que definiu as estratégias da empresa para este ano, a proposta de consolidar a presença no setor esportivo estava como uma das metas a serem alcançadas. Pelo terceiro ano consecutivo a TV Brasil exibiu o Campeonato Brasileiro de Futebol da Série C. Em 2014, nas transmissões, a EBC manteve bons patamares de audiência, alcançando uma média de 1,21 em Recife, 0,81 em Salvador e 0,51 no Distrito Federal. Também em 2014, pela primeira vez, a EBC firmou contratos de sub licenciamento dos direitos da Série C, no valor de $\mathrm{R} \$ 1,17$ milhões e de quotas de publicidade institucional, no valor de $\mathrm{R} \$ 1,58$ milhões, totalizando $\mathrm{R} \$ 2,75$ milhões. (EBC, 2015).

A adesão às transmissões esportivas é uma das características do telespectador de futebol. Para o pesquisador espanhol Joseba Iriarte (2010), o público se envolve nas transmissões esportivas mais do que em qualquer outro programa e isso gera audiência, o que 
permite que ele "viva o jogo com mais entusiasmo e atenção" (IRIARTE, 2010, p. 74). Outra vantagem destas transmissões de futebol e que tornam um programa atraente é o formato do programa: com a aquisição seguida dos direitos de transmissão, uma emissora consegue atrair o telespectador-torcedor e isso contribui para a audiência durante o campeonato.

Bucci ironiza a questão da audiência ao dizer que "os administradores da TV pública vivem se declarando preocupados com a possibilidade de perder público. Segundo o pesquisador, "nada poderia ser tão alucinado: eles não podem perder o que não têm" (BUCCl, 2013, p. 134). Mesmo assim, têm medo de perder (ainda mais) audiência e, aí, de levar bronca dos chefes, os governantes" (idem, 2013, p.134). O jornalista ressalta que o verdadeiro chefe é o cidadão e se perderem o medo do "suposto chefe" é que deixarão de temer a falta de audiência e, como consequência, irá atrair o público.

Em 2014, a EBC criou uma página chamada "EBC para a sociedade" como um espaço de prestação de contas das atividades realizadas durante o ano e perspectivas para 2015, em conteúdos multiplataforma, com o objetivo de dar uma visão geral sobre a empresa. Em relação à audiência, "em seis das principais capitais brasileiras, mais de 32 milhões de pessoas assistiram à programação da TV Brasil via televisão aberta" (EBC NA SOCIEDADE, 2014).

Porém, esses dados foram questionados pelo jornalista Maurício Stycer (2014) e pelo escritor Marcelo Rubens Paiva (2014), alegando que "as seis principais capitais brasileiras (São Paulo, Rio, Salvador, Brasília, Fortaleza, Belo Horizonte) somam cerca de 29 milhões de habitantes, segundo dados atualizados do IBGE (Instituto Brasileiro de Geografia e Estatística). A audiência propalada pela TV Brasil nestas cidades supera a própria população" (STYCER, 2014; PAIVA, 2014).

E no que se refere à audiência, identificou-se também nesta análise um elemento de comunicação: o valor-notícia. O valor-notícia, como já mencionado, é um componente da noticiabilidade e ajuda os profissionais de imprensa a saber quais os acontecimentos que são considerados suficientemente interessantes, ou que pode tornar-se candidato a se transformar em notícia (WOLF, 2005; TRAQUINA, 2005).

Para o filósofo italiano Mauro Wolf (2003), dois fatores se destacam para definir critérios do valor-notícia: os substantivos (a avaliação direta do acontecimento conforme a importância e o interesse da notícia) e os contextuais (referentes ao contexto de produção da notícia).

No caso da transmissão de eventos esportivos, o gerente do Núcleo de Esportes da EBC, Carlos Gomes, em entrevista à Revista do Conselho Curador, em 2014, justifica a importância e o interesse na cobertura esportiva. Para ele "um evento esportivo tem interesse jornalístico, mas acaba sendo espetáculo. Temos que tratar o esporte como evento [nas transmissões], e como cobertura jornalística nos jornais. São duas coisas diferentes" (CRISPI, 2014, p.12).

Para Wolf (2003) grande parte da programação de TV é consumida como "televisão" e não se deve a um programa específico, já que o telespectador se sente atraído por um gênero que o satisfaz. Na televisão, o esporte é uma das poucas práticas que tem amplo espaço, com vários programas especializados (BORELLI, 2002). A partir desta consideração, 
a escolha de uma transmissão esportiva, no caso, da Série C, deveria ganhar espaço diferenciado quando acrescenta informações que vão ao encontro com a missão da EBC: criar e difundir conteúdos que contribuam para a formação crítica das pessoas. O que pode ser um diferencial da cobertura, atrair audiência e, de certa forma, "[a TV Brasil deveria] estar a serviço do povo, cumprindo seu papel de TV Pública" (Professor e ex-gestor esportivo entrevistado pelos autores em 2015).

No caso da TV Brasil, a pesquisa quantitativa realizada pelo Instituto Análise, aponta que, embora a emissora esteja incorporada aos hábitos dos telespectadores, não há "uma frequência de audiência definida, podendo variar entre diária, duas, três ou 4 vezes por semana, ou apenas aos finais de semana" (BRASIL, 2015, p. 20). E apesar de que uma TV é pública parece não fazer diferença na escolha por uma emissora, algumas características tidas como intrínsecas a essa categoria de TV parecem ter papel relevante na audiência.

Quanto à emissora, os especialistas entrevistados destacaram três pontos fortes da existência dela: 1) a narrativa que busca a reflexão "mais do que a emoção mais simples, característica da mídia comercial" (Profissional de Comunicação, entrevista aos autores em 2015); 2) a sensibilização de públicos maiores a partir do uso tático das transmissões esportivas "digamos assim, a ampliação do leque de opções e de alguma forma, repercussão midiática" (Gerente-executivo, entrevista aos autores em 2015); 3) abrangência nacional e linguagem não regionalizada, porque "o Brasil são vários países dentro do mesmo país" (Professor e ex-gestor esportivo, entrevista aos autores em 2015).

Por outro lado, os entrevistados consideraram como sendo pontos negativos em relação à existência de uma TV Pública: 1) a falta de universalidade do acesso, ou seja, ainda a população brasileira não tem acesso fácil ao sinal da TV Brasil; 2) necessidade de alargar a base de oferta de produtos para além do futebol, pois, segundo o Gestor-Executivo "o futebol é o pão cotidiano das emissoras especializadas, o futebol está muito presente e tem permanência nas grades das tevês abertas; 3) e a identidade da emissora que poderia ser melhor comunicada/melhorada.

O esporte, na TV Pública, de acordo com os especialistas ouvidos para este estudo, deveria ser menos voltado para o espetáculo e mais jornalismo, como forma de se colocar telespectador dentro de campo, com informações da cidade onde a partida é transmitida, história dos clubes, entre outras. Além disso, a transmissão de modalidades olímpicas na grade da TV Pública seria um diferencial para uma cobertura com viés associado à cidadania, e que se relaciona à visão e valores da empresa.

Em relação ao futebol, destaca-se que a modalidade é elemento importante na cultura brasileira e que "é um elemento importante na cultura brasileira, e a TV pública deve dar atenção a ele, mas sem exagerar" (Profissional de Comunicação, entrevista aos autores em 2015). Os entrevistados consideram que deveria ser oferecido como um conteúdo diferenciado, pela perspectiva da cultura e transmitir campeonatos de divisões inferiores, dando espaço àqueles que não têm visibilidade na mídia comercial.

$\mathrm{Na} \mathrm{EBC}$, os documentos que regulamentam a linha editorial para o esporte são os Planos de Trabalho e o Manual de Jornalismo. Esses documentos trazem valores como priorização do esporte na cobertura jornalística, complementariedade dos sistemas de 
comunicação, integração de plataformas, inclusão social e cultura, pluralidade de temas e modalidades, inovação, abordagem diferenciada e diferenciação entre o esporte de alto desempenho e o amador. A prioridade da cobertura deve ser sempre dada ao esporte que o cidadão pratica e não ao que vê.

\section{CONCLUSÕES E LIMITAÇÕES DO ESTUDO}

A predominância do futebol nas transmissões esportivas da TV Brasil indica que esta pode ser uma maneira de atrair um público e consequente visibilidade para a emissora. Mas, ainda não há estudos científicos que indicam como esse telespectador é visto pela TV Pública e de que forma ele avalia a emissora.

Embora entre os objetivos estratégicos da emissora esteja o de alcançar a qualidade de excelência de conteúdos e contar com um dos indicadores de desempenho o índice de audiência, a TV Brasil deveria priorizar a criação de um padrão e fortalecer a marca em seus produtos e no conteúdo exibido.

Se hoje a emissora pública conta com alguma referência na transmissão do Campeonato Brasileiro da Série C, é porque manteve o produto durante um período (2015 foi o terceiro ano que o futebol está na grade da programação), no mesmo horário, nos mesmos dias da semana (sábado e domingo).

De certa forma, ainda falta experimentar novos formatos para ampliar a base de público da emissora. Falta identificação do telespectador com o canal que exibe a partida do time favorito. O futebol tem prioridade no jornalismo esportivo no noticiário, nos programas e nas transmissões esportivas. Outras modalidades dificilmente contam com espaço em canais abertos. Se as emissoras, sejam elas públicas ou privadas, não exibirem outros esportes, não há como saber se o telespectador tem ou não interesse maior pelo futebol.

Para responder à questão de pesquisa deste estudo - se a emissora, ao contar com transmissões de futebol na programação cumpre sua missão enquanto TV pública - foram ouvidos três profissionais da área da administração, comunicação e gestão esportiva, e suas observações foram confrontadas com os referenciais teóricos.

Quanto ao objetivo deste estudo, que foi o de verificar se a missão, visão e valores da EBC eram coerentes com a proposta de produção no esporte em uma emissora pública, conclui-se que eles são atingidos em parte. É questionável o quanto as transmissões do futebol contribuem para a formação crítica das pessoas (missão) pelo fato de que são feitas no formato clássico, tradicional, tais como as das emissoras comerciais. Não há a preocupação jornalística, por exemplo, em pautar reportagens no espaço de pré-jogo - em que um apresentador e os comentaristas da partida participam de discussões prévias sobre a partida - que proporcionem a reflexão do telespectador além da transmissão da partida. Ele "consome" o produto futebol e não se sente atraído para permanecer acompanhando a programação da emissora.

Quanto à visão da empresa, a de ser referência em comunicação pública, percebe-se que ainda há um caminho a percorrer. Um dos entrevistados destaca o desconhecimento e 
conceitos construídos pela mídia, que não refletem a natureza da TV Pública. Diferenciar entre TV governamental ou estatal de TV pública é um dos desafios da TV Brasil e da EBC para a construção da comunicação pública no país. Além disso, ao conhecer a emissora, o público pode participar do processo de diversificação da programação, por exemplo, com conteúdos relevantes e que contribuam para a construção e formação da cidadania.

Por fim, entre os valores da empresa, mostra-se que a diversidade cultural brasileira está presente nas transmissões esportivas, por meio dos clubes participantes do campeonato e que representam as cinco regiões do país. De certa forma, este é o principal elemento de identificação e que vai ao encontro da proposta de transmissão do futebol da terceira divisão nacional. Outros campeonatos de futebol foram transmitidos durante o ano de 2015, como o Brasileiro e o Mundial Feminino, no Canadá. Neste caso, a questão de gênero também foi representada na emissora pública.

Este estudo espera contribuir com a reflexão de como o tema "TV Pública" precisa ser estudado, sobretudo na área da gestão do esporte. Entender de que maneira uma emissora pública pode contar com o esporte sendo o vetor na construção da cidadania em um país de dimensões continentais como o Brasil.

Como limitação de pesquisa, consideramos que ao contar com pouca participação de agentes ligados à comunicação pública e à gestão do esporte, o debate fica limitado para que outras reflexões sobre a discussão proposta. Como sugestão de estudos futuros, espera-se que a TV Brasil conheça o perfil do telespectador de esportes, saiba quais são seus anseios e motivações para acompanhar as transmissões, e como esse telespectador-torcedor vê a emissora como produtora de conteúdo esportivo.

\section{REFERÊNCIAS}

BAHIA, J. A. A sociedade do espetáculo. Observatório da Imprensa. Rio de Janeiro, 2005. Disponível em: http://observatoriodaimprensa.com.br/speculum/a-sociedadedo-espetaculo. Acesso em: 01 de outubro de 2015.

BARDIN, L. Análise de conteúdo. Lisboa: Edições 70, 2007.

BOURDIEU, P. Sobre a Televisão - A influência do jornalismo e os Jogos Olímpicos. Rio de Janeiro: Jorge Zahar Editor, 1997.

BRITTOS, V. C.; CABRAL, A. Economia Política da Comunicação: interfaces brasileiras. Rio de Janeiro: E-papers, 2008.

BUCCI, E. É possível fazer televisão pública no Brasil?. Novos Estudos-CEBRAP, n. 88, p. 05-18, 2010.

Sobre a independência das emissoras públicas no Brasil. Revista Eptic online, v. 15, n. 2, p. 121-136, 2013.

BRASIL. Presidência da República. Secretaria de Comunicação Social. Pesquisa Brasília de Mídia 2015: hábitos de consumo de mídia pela população brasileira. Brasília: Secom, 2014.

CARTA DE BRASÍLIA. Manifesto pela TV Pública independente e democrática. I Fórum Nacional de TVs públicas, 2007. 
CHADE, J. Final da Copa do Mundo foi vista por mais de um bilhão de pessoas. São Paulo: O Estado de São Paulo, 2014 - Disponível em: http://esportes.estadao.com.br/noticias/ futebol,final-da-copa-do-mundo-foi-vista-por-mais-de-um-bilhao-de-pessoas, 1564835. Acesso em: 15 de outubro de 2015.

CRESWELL, J. W. Projeto de Pesquisa: métodos qualitativo, quantitativo e misto. $3^{\mathrm{a}}$ ed. Porto Alegre: Artmed, 2010.

CRISPI, P. O lugar do esporte na Comunicação Pública. Revista do Conselho Curador - Empresa Brasil de Comunicação (EBC), Vol. 3, 2014. Disponível em: http://www. ebc.com.br/sites/default/files/revista_conselho_curador_edicao3.pdf. Acesso em: 26 de junho de 015 .

DA MATTA, R. Antropologia do Óbvio. Revista USP, São Paulo, USP, n.22, 1994.

DAYAN, D. The peculiar public of television. Media, Culture \& Society, v. 23, n. 6, p. 743-765, 2001.

DE AGUIAR, L. A.; PROCHNIK, L. Quanto vale uma partida de futebol? A relação entre televisão e futebol no cenário midiático contemporâneo. Logos, v. 17, n. 2, p. 51-64, 2010.

EBC - Empresa Brasil de Comunicação. Planejamento Estratégico-2016. Brasília: EBC, 2015. EBC - Empresa Brasil de Comunicação. Planejamento Estratégico 2012-2020. Brasília. EBC, 2012.

EBC - Relatório da Ouvidoria - Outubro/2015 - Disponível em: http://www.ebc.com. br/sites/default/files/relatorio_outubro_2015_web.pdf. Acesso em: 01 de dezembro de 2015.

EBC-MANUAL DE JORNALISMO. Empresa Brasil de Comunicação. Manual de Jornalismo da EBC. Brasília: EBC, 2013.

EBC NA SOCIEDADE. EBC para a sociedade. Brasília-DF - Disponível em: http://www. ebc.com.br/ebc-para-a-sociedade. Acesso em: 30 de julho de 2015.

FLICK, U. Qualidade na pesquisa qualitativa: Coleção Pesquisa Qualitativa. Bookman Editora, 2009.

GERHARDT, T. E.; SILVEIRA, D. T. Métodos de pesquisa. Porto Alegre: Plageder, 2009.

IRIARTE, J. B. El eterno problema del fútbol televisado en España: una perspectiva histórica de la lucha por los derechos de retransmisión de la Liga de Fútbol Profesional (LFP). Comunicación y Sociedad. Vol. 23 (2), p. 71-96, 2010.

KELLNER, D. A cultura da mídia e o triunfo do espetáculo. Líbero, 6(11), p.01-15, 2007. . Cultural studies, multiculturalism, and media culture. Gender, race, and class in media: A critical reader, p. 7-18, 2011.

LEAL FILHO, L. A melhor TV do mundo: o modelo britânico de televisão. São Paulo: Summus Editorial, 1997.

. A televisão pública brasileira, um vazio histórico. XVI Encontro da Compós Curitiba-PR, v. 16, 2007.

LOPES, I. S. Televisão pública e modelos de financiamento: análise do caso brasileiro1. Eptic online: revista electronica internacional de economia política da informaçao, da comuniçao e da cultura, v. 17, n. 1, p. 33-48, 2015.

MARTIN-BARBERO, J. Televisión Pública, Television Cultural: Entre la renovación y la invención. In: Rincon, O. (comp.) Televisión Publica, del consumidor al ciudadano. Bogotá, CAB/FES, p.35-69, 2001. 
MAZZIOTTI, N. Os gêneros televisivos na televisão pública. RINCON, Omar (Org.). Televisão pública: do consumidor ao cidadão. São Paulo: SSRG, 2002.

MOYSES, D.; AZEVEDO, F.; VALENTE, J.; PEREIRA S. Sistemas Públicos de Comunicação no mundo - Experiências de doze países e o caso Brasileiro. São Paulo: Paulus, Intervozes, 2009.

NAZARENO, C. A implantação da TV Pública no Brasil. Brasília: Biblioteca Digital da Câmara dos Deputados, 2007. Disponível em http://bd.camara.gov.br/bd/handle/ bdcamara/1104. Acesso em: 15 de outubro de 2015.

ORTIZ, P. H. F. Perspectivas e desafios na consolidação do campo público de televisão no Brasil. Revista ABTU, p. 32, 2010.

OTONDO, T. M. Televisão pública: para quem e para quê? São Paulo, Annablume, 2012.

POZZI, L.F. O patrocínio esportivo como veículo de marketing. Dissertação de Mestrado em Administração, EAESP - Fundação Getulio Vargas, São Paulo, 181p., 1996.

REIN, I.; KOTLER, P.; SHIELDS, B. Marketing Esportivo: A reinvenção do esporte na busca de torcedores. Porto Alegre: Bookman Editora, 2009.

ROCCO JÚNIOR, A. J. Cultura organizacional e a gestão de equipes de alto rendimento: os casos FC Barcelona, Sporting Club de Portugal e AFC Ajax. Podium, v. 3, n. 2, p. 12, 2014.

. O Atleta como Celebridade e o Esporte como Espetáculo no Discurso da Mídia Impressa Brasileira: o caso dos Jogos Olímpicos de Londres 2012. XXXVI Congresso Brasileiro de Ciências da Comunicação - Intercom. Manaus, Intercom, 2013.

PAIVA, M. R. Pilantragem na TV Brasil. O Estado de São Paulo, 2014. Disponível em: http://cultura.estadao.com.br/blogs/marcelo-rubens-paiva/pilantragem-na-tv-brasil. Acesso em: 30 de julho de 2015.

SAVENHAGO, I. J. S. Futebol na TV: evolução tecnológica e linguagem de espetáculo. Verso e Reverso, v. 25, n. 58, p. 22-31, 2011.

SENADO FEDERAL. Constituição da República Federativa do Brasil. Brasília: Senado, 1988. STYCER, M. Com "contabilidade criativa", TV Brasil sugere audiência maior que a real. UOL, 2014. Disponível em: http://mauriciostycer.blogosfera.uol.com.br/2014/12/17/ com-contabilidade-criativa-tv-brasil-sugere-audiencia-maior-que-a-real. Acesso em 30 de julho de 2015.

TRAQUINA, N. Teorias do Jornalismo. Vol. II. A tribo jornalística - uma comunidade interpretativa transacional. Florianópolis: Insular, 2005.

VÉRAS, A. S.; JÚNIOR, S. Cobertura cotidiana da política no telejornal brasileiro: o que vai ao ar sobre política no Jornal Nacional? Estudos em jornalismo e mídia, v. 8, n. 1, 2011. VERGARA, S. C. Métodos de pesquisa em administração. 5a Ed. São Paulo: Atlas, 2012. WOLF, M. Teorias da comunicação de massa. São Paulo: Martins Fontes, 2003.

Recebido em: setembro/2016 Aprovado em: dezembro/2016 